\title{
The development of physical preparedness of student young people
}

\author{
${ }^{1}$ Muratov Muzaffar Shermamatovich., ${ }^{2}$ Khusainov Shamsidin Yalgashevich, \\ ${ }^{3}$ Sattarov Karshiboy Narkulovich \\ ${ }^{1}$ Samarkand Medical Institute., Uzbekistan. \\ ${ }^{2}$ Samarkand State Institute of Architecture and Civil Engineering,.Uzbekistan. \\ ${ }^{3}$ Samarkand Medical Institute., Uzbekistan. \\ E-mail: shamshixusainov@gmail.com
}

\begin{abstract}
In the modern world there are a number of unsolved problems concerning the physical development of youth. At the present time this problem is actual. There is an active regression in the physical development of incoming entrants. This problem starts in early adolescence, from the school bench. At the moment of building the foundation in the physical development of schoolchildren is reducing the level of physical fitness. The gap in physical development at an early stage will be reflected in the future. Therefore, it is very important to pay due attention to active physical development. Due to lack of time, lack of necessary equipment, weak material and technical base of the educational institution, physical education is conducted in a simplified form and does not allow teachers to achieve the necessary pedagogical effect. In order to raise the importance of physical education and sport among school-age students, it is recommended that a number of measures be taken to promote it through the mass media, sporting events and competitions.
\end{abstract}

Keywords

Physical fitness, youth, physical development, student, physical qualities.

Article Received: 18 October 2020, Revised: 3 November 2020, Accepted: 24 December 2020

\section{Introduction}

Physical fitness is a specialized process of physical education, aimed at preparing a person for work and protecting the Motherland (special physical training, for example, for astronauts, pilots, athletes, etc.). This is one of the most important components of physical education. Physical training consists in upbringing (development) of those involved in physical (motor) qualities. Distinguish between general and special physical training. She is a process strengthening health, achieving a certain level of physical development, education of motor qualities. Physical training of university students is aimed at strengthening health, development of body forms and functions, expansion of motor skills, physical development. Since, physical development obeys objective social and natural laws, then it should be considered not only as a process, but also as a result of the development of the functional capabilities of the human body, taking into account its individual characteristics, living conditions and activities in society

\section{INTRODUCTION}

The problem of improving physical fitness, health of student youth remains the most important state problem.

\section{Main part}

Maintaining and strengthening the health of student youth is one of the priority tasks facing higher education today. Each institution of higher education should strive to improve the level of physical development of students, develop their sports skills and promote a healthy lifestyle. The role of students' physical fitness is multifaceted. Technological progress, the rapid development of science and the ever-increasing amount of new information necessary for a modern specialist, make the student's educational activity more and more intense and intense. Accordingly, the importance of physical culture also increases as a means of optimizing the mode of life, active rest, 
maintaining and increasing the efficiency of students throughout the entire period of study. Physical education in unity with mental, moral, aesthetic and labor education ensure the all-round development of the individual. Moreover, these aspects of the general process of education are largely manifested in the most appropriately organized process of physical education. In modern physical education, physical education (the unity of general and special physical training, the development of forms and functions of the body, physical qualities, motor skills and abilities) allows a versatile influence on the personality. At the same time, many socially significant results of physical education are currently achieved only partially. All this testifies to the problem of physical fitness of students. Physical training is the main component of a person's physical education. It involves mastering a wide range of motor skills and abilities that help to successfully specialize in any chosen activity. The main content of physical training is the most important types of human movement: walking, running, jumping, throwing, swimming, skiing, overcoming obstacles. Physical training develops a person's ability to quickly master new types of movements and apply the acquired skills in practice and in everyday life. The basis of physical fitness is systematic physical exercises and sports, as a result of which various motor skills and physical qualities are formed and improved, fitness gradually develops, characterized by a complex of morphological and functional shifts in the body's activity, improved mechanisms of regulation and adaptation to physical loads, acceleration of recovery processes. Physical culture and sports in a higher educational institution are an integral part of the formation of the general professional culture of a modern specialist, effective means of social formation of future specialists, comprehensive and harmonious development of the personality, and preservation of the health of students. The main goal of physical education among student youth is the formation of physical culture of the individual and the ability to use various means of physical culture, sports and tourism for the preservation and strengthening of health, psychophysical training and self-preparation for future professional activity and life. In the process of studying at the university in the course of physical education, the solution of the following educational, educational, developmental and health-improving tasks is envisaged: - education of students of high moral, volitional and physical qualities, readiness for highly productive work; preserving and strengthening the health of students, promoting the correct formation and allround development of the body, maintaining high performance throughout the entire period of study; - comprehensive physical training of students; professionally applied physical training of students, taking into account the peculiarities of their future work activity and training; - instilling in students the conviction of the need to regularly engage in physical culture and sports. Physical education classes at the university are aimed not only at mastering various motor actions and the development of basic physical qualities, but also the formation of special systematized knowledge, interests, motivations, which contributes to the development of students' need for constant physical self-improvement and self-education.

Physical development reflects the processes of growth and development of the organism at certain stages of postnatal ontogenesis (individual development) when the most vivid transformations of genotypic potential into phenotypic manifestations take place. Peculiarities of physical development and physique of a human being largely depend on its constitution. Physical development, along with birth rate morbidity and mortality, is one of the indicators of the population health level. Processes of physical and sexual development are interconnected and reflect general regularities of growth and development, but at the same time significantly depend on social, economic, sanitary and other conditions, the impact of which is largely determined by the age of a person. Physical development is 
understood to be the continuously occurring biological processes. At each age stage they are characterized by a certain complex of morphological, functional, biochemical, mental and other properties of the organism connected with each other and with the external environment, and the reserve of physical forces caused by this peculiarity. A good level of physical development is combined with high indicators of physical training, muscle and mental performance. Adverse factors affecting the intrauterine period and early childhood can disrupt the body's development sequence, sometimes causing irreversible changes. Thus, environmental factors (conditions of nutrition, upbringing, social, presence of diseases, etc.) in the period of intensive growth and development of a child may have a greater influence on growth than genetic or other biological factors. The basis for assessment of physical development is the parameters of growth, body weight, development proportions of individual parts of the body, as well as the degree of development of functional abilities of the body (lung capacity, muscle strength of the hands, etc.); development of muscle and muscle tone, the state of posture, musculoskeletal system.] Historically, physical development has been judged mainly by external morphological characteristic.

Physical education of student youth, firstly, should provide a high degree of development of motor qualities, acquisition of knowledge, skills and abilities necessary for successful professional activity in order to increase educational and labor activity, preserve and promote health. Secondly, it should encourage young people to engage in systematic physical exercise. Third, promote the development of social activity, influence the formation of spiritual world, moral and aesthetic development of the student's personality.

There are currently unresolved problems with the physical development of youth. One global problem in the physical development of young people arises from the school bench. Most schoolchildren today live on the same daily routine. They wake up in the morning, eat breakfast not with the healthiest food, and then go to school, where they spend seven to eight hours sitting at the desk. After that, they go home, do their homework, and spend the rest of the day at the computer and phone. Of course, not all students follow this regime, but they are very few. In addition, most high school students have bad habits and lead a passive lifestyle. That is why students with poor physical fitness enter universities. The educational process of physical education in higher education institutions is carried out in the following forms: academic studies during school hours, independent exercises and sports for students during extra-curricular activities, physical exercises during the school day, mass health-improvement, physical culture and sports activities. These forms of physical exercises are interconnected, complement each other and represent a single process of physical improvement. To increase the effectiveness of the process of physical education of students it is necessary to adhere to the following methodological requirements:

To observe the adequacy of the content of physical training to the individual state of the person;

- to ensure harmonization and optimization of physical training through the use of new nontraditional physical activities;

- to give freedom to choose forms of physical activity, combining with the desires and abilities of each person;

- to strengthen the educational aspect in the content of the educational material in order to deepen students' mastery of the system of knowledge, skills and abilities of physical selfimprovement and, on this basis, to form interest in healthy lifestyle;

\section{The purpose of the study}

To investigate the frequency and quality of correct motor performance by adolescents and youth. To demonstrate the vital need for systematic sports and various physical exercises. 
- purposefully create in students a conscious need and a steady habit to take care of their health and physical self-improvement.

\section{The results of the research}

Flexibility, dexterity, speed, strength and endurance are among the leading characteristics that affect a person's physical development. Improving one or each of these qualities enhances health and promotes harmony [1].

Children are underdeveloped physically. In particular, this occurs in the early stages of body formation. In most schools, in primary schools, physical education is led by class leaders. These teachers were not associated with sports. Theoretical knowledge is not enough to provide a full practical exercise. The most important initial stage lasts four years, but, unfortunately, it is incomplete. In primary school, children must develop actively, and instead they will have a gap in physical development.

Statistics indicate that currently more than 40 per cent of school leavers have two or more chronic illnesses, and 30 per cent of conscripts to the armed forces are unsuitable for fixed-term service due to health reasons. About $40 \%$ of young men of draft age cannot meet the CFC norms even for a satisfactory assessment [2]. Various sociological studies show that the number of students sent to special medical groups as a result of a medical examination reaches $50 \%$ of the total number of students, and the level of physical health of young people decreases directly depending on the course of study [3].

Pupils are already transitioning to middle classes with poor physical fitness, as there was a global gap in the initial phase. Only a few children find themselves with good physical fitness, because in parallel to the learning process, they were engaged in sports schools, in additional sections and clubs. Physical education in middle and high schools seems to be boring and unnecessary for pupils. In high school, teachers and students have a specific goal, namely, to prepare for higher education. In this regard, the university starts full academic load and less and less time is spent on sports. Therefore, the number of healthy students decreases with age.

According to statistics, about 23-26\% of healthy children of primary school age are characterized by low mobility of nervous processes, they are called "slow children". Of course, they have general development, but their reactions are slow, and their efficiency is 2-3 times lower than that of "fast children". They also have poorly developed movement coordination. They react to the load with fast heartbeats and breathing. From this we can conclude that the teacher has many tasks to perform in a modern physical education lesson. How in 45 minutes of the lesson to have time to carry out the educational and training process, taking into account the physical capabilities of students, to prepare them to pass the norms "Alpomysh and Barchina", and not to go beyond the curriculum? Due to lack of time, lack of necessary equipment, weak material and technical base of the educational institution, physical training is held in a more simplified form. Also, it should be noted that the prestige of the profession of school physical education teacher and coach in children's and youth sports schools of various orientations is rapidly declining in society

\section{Conclusion.}

Thus, the article investigates the main reasons for physical "unpreparedness" of students. So, how to solve this problem? First, to increase the importance of physical education and sports among school-age students should be a series of measures to promote them through the media, sports events, competitions, etc. Secondly, in order to raise the importance of the profession of physical education teacher, it is necessary to increase their salaries and provide employment for graduates of physical education faculties in various universities. Thirdly, in order to increase the hours of physical training of students, it is necessary to revise the existing curricula and develop optimal ones, taking into account the higher physical employment of students. B - 
Fourth, in order to increase funding for physical education of students, develop a number of financial and material-technical support programmers for general education institutions aimed at providing conditions for sports and physical education city.

The proposed measures will make it possible to intensify sports and mass work of students outside school hours, increase their motor activity, improve their performance and health in general. In addition, increased physical activity of schoolchildren will help to meet their social needs for self-realization. Various types of physical education and sports activities should be organized in schools in order to give pupils a choice according to their abilities and wishes. This will have an impact on developing an interested and conscious attitude towards physical activity among students.

\section{References}

[1] Batenko E. M., Bugai, M.V. Conditions of the students' healthy way of life formation in physical education (in Russian) // Society. History. Modernity. 2018.

[2] Kozlov A.V. Alternative method of sports-oriented physical education of students of humanitarian universities: Voronezh. 2006.

[3] Osipov A.Y., Golm L.A., Mikhailova S.A. Formation of health saving competences of future specialists by means of physical education //. 2012. T. 2, C. 178-182W.-K. Chen, Linear Networks and Systems. Belmont, CA: Wadsworth, pp. 123-135, 1993.

[4] Encyclopedia of physical training: Methodical bases for the development of physical qualities / EN. Zakharov, A.V. Karasev, A.A. Safonov, - M Leptos, 1994.

[5] Physical culture of the student and life. Textbook for universities / V. I. Ilinich-M: Gardariki,2010.
[6] Ilyinich V.I.Student sports and life. 1995.

[7] Mass physical education at the university.V.A.Maslyakova,V.S.Matyazho va. 1991.

[8] Physical education of students and pupils. N. Ya.Petrov, V.Ya. Sokolov.1988

[9] Goloshchapov B.R.The history of physical culture and sports.M., 2000.

[10] A.V.Zherebtsov Physical culture and labor - Moscow. 1986.

[11] Maksimenko A.M.Fundamentals of the theory and methods of physical culture.M., 1999.

[12] Matveev L.P.Theory and methodology of physical culture.M., 1991.

[13] Rafin A. Ya. Physical culture.M., 1989.

[14] Kholodov Zh.K.Kuznetsov V.S.theory and methodology of physical education and sports.M., 2003.

[15] Anischenko V.S. Physical culture: Methodical and practical classes of students: Textbook. - M .: Publishing house of RUDN, 1999.

[16] Vilensky M.Ya., Safin R.S. Professional orientation of physical education of students of pedagogical specialties. -High school, 1989.

[17] Vilensky M. Ya. Ilyinich V.I. Physical culture of mental workers -M: Knowledge, 1987.

[18] Grinenko M.F., Sanoyan G.G. Labor, health, physical culture. - M: FiS, 1974.

[19] Ilyinich V.I. Student sports and life. M.:"Aspect Press" 1995.

[20] Ilyinich V.I.Professional-applied physical training of university students. - M; Higher. shk., 1978.

[21] Physical education: Textbook. Ed. V.A. Golovin. M., 1983. 
[22] Baronenko V.A., Rapoport L.A. Health and physical education of the student. M., Alpha - M, 2003

[23] Furmanov A.G., Yuspa M.B. Recreational physical culture. Minsk, "Theseus", 2003

[24] Yevseev Y.I. Physical education. R-onD., "Phoenix", 2002 